\title{
The Effects of Copper Addition on the compression behavior of Al-Ca Alloy
}

\author{
Prabhash Jain, Karan Singh Verma \\ University Institute of Technology, Barkatullah University, Bhopal India -462026
}

\begin{abstract}
The $\mathrm{Al}$-Ca-Cu alloys containing varying amount of $\mathrm{Cu}$ are used to study the effect of $\mathrm{Cu}$ addition on their deformation behavior at varying strain rate $(0.001 / \mathrm{s}, 0.01 / \mathrm{s}, 0.1 / \mathrm{s}, 1 / \mathrm{s})$. The material is prepared using stir casting technique The yield stress, flow stress and elastic limit are measured from the true stress-strain graph .The Strain Rate sensitivity and strain hardening exponent are also determined for each material at different strain rate. The Strain Rate Sensitivity of this alloy is very low. These values strongly demonstrate that compressive deformation of $\mathrm{Al}-\mathrm{Ca}-\mathrm{Cu}$ alloys almost independent to the strain rate at room temperature deformation.
\end{abstract}

Keywords: Compressive deformation ; Strain Rate ; Strain Rate Sensitivity ; Strain Hardening exponent ; Strength Coefficient ;Copper Contents.

\section{Introduction:}

The demands of rapidly evolving technology call for continuous research and development efforts aimed at invention of novel casting aluminum alloys. It often happens that the standard casting alloys, including high-quality materials, do not satisfy the rigorous requirements for applications in different areas of technology. Alloys containing small amounts of eutectic (e.g., on the basis of the $\mathrm{Al}-\mathrm{Cu}, \mathrm{Al}-\mathrm{Mg}$, and $\mathrm{Al}-\mathrm{Zn}-\mathrm{Mg}$ systems) have significant advantages - better mechanical properties [1]. Aluminum and its alloys have potential applications in aerospace and automotive industry because of its higher specific strength and stiffness [2-4].In general it is well known that the pure Aluminum is comparatively softer than other. For applications requiring greater mechanical strength, it is generally alloyed with other elements such as copper, magnesium, manganese, iron, silicon and zinc. The details of the effect of different alloying elements on the microstructure and mechanical behavior of aluminum and its alloys are reviewed by stake [5]. The Addition of $\mathrm{Mg}, \mathrm{Na}$ and $\mathrm{Sr}$ in small quantities influenced the eutectic transformation of Al-Si cast alloys and modified silicon morphologies to a great extent and thus improve its strength and toughness [6]. It is further reported by Dash and Makhlouf [7] that the castability of Al-Si alloys improved, hydrogen absorption decreased and microstructure got refined and modified due to addition of $\mathrm{Mg}, \mathrm{Mn}, \mathrm{Cu}, \mathrm{Sr}$ and Ti. All these factors lead to higher strength and ductility. Alloying in copper can significantly improve mechanical strengths and raise the softening temperatures. However, additions of alloying elements also reduce electrical and thermal conductivity. Among the three alloying strengthening mechanisms, namely, solid solution hardening, precipitation hardening, and dispersion strengthening, solid solution hardening has the most detrimental effects on the conductivity [8] and is the least favored mechanism to obtain high conductivity, high-strength copper alloys. Cold work can significantly increase the strength of pure copper and has a relatively moderate effect on conductivity.[8]However, coldworked copper can be softened at relatively low temperatures $\left(200^{\circ} \mathrm{C}\right)$ because of its low recrystallization temperature.[9] A recent study has shown that ultrahigh-strength and high-conductivity copper can be produced by introducing a high density of nanoscale twin boundaries.[10] Copper and its alloy possess high strength and high conductivity in the prime-aged condition, and good fracture toughness and fatigue properties in both nonirradiated and irradiated conditions.[11] Plastic strengthening coefficient and strain-hardening exponent of the $\mathrm{Ca}$ added alloy varies with strain rate.[12] These values for this alloy are considerably higher than for 7178 alloy without $\mathrm{Ca}$ addition [12]. The compressive deformation behavior of $\mathrm{Ca}$ added 7178 alloy as a whole varies marginally with strain rate. The strain rate sensitivity of the alloy at ambient temperature is noted to be very low.[12]The strain hardening exponent of Al-Ca alloy is rated to be the maximum for $2 \mathrm{wt} \% \mathrm{Ca}$. whereas $2 \mathrm{wt} \%$ $\mathrm{Ca}$, the plastic strengthening coefficient is noted to be the minimum.[13] No attempts have been made and reported on the Effect of Cooper Addition on the deformation behavior of Al-Ca-Cu Alloy using stir casting method . In this present paper attempt is made and characterize in the terms of compressive deformation behavior at varying strain rates at room temperature.

\subsection{Material Synthesis:}

\section{Experimental Procedure:}

$\mathrm{Al}-\mathrm{Ca}-\mathrm{Cu}$ alloy is prepared by stir casting technique .This technique involved melting of $\mathrm{Al}-\mathrm{Ca}-\mathrm{Cu}$ alloy in the electric resistance furnace .Pure commercial aluminum ingot was firstly cleaned and melt. 
Laboratory grad $\mathrm{Ca}$ granules were then added into the melt through mechanical string. Firstly preheated $\mathrm{Al}$ and $\mathrm{Cu}$ pieces were put in the Crucible and start the melting. After maintaining the temperature of melt between $700^{\circ} \mathrm{C}$ to $800^{\circ} \mathrm{C}$, a vortex was created within the melt using a mechanical stirrer. When temperature reaches to $800^{\circ} \mathrm{C}$ the $\mathrm{Ca}$ granules (2wt \%) were also added to melt, at same time mechanical string was also in process. Mechanical string provides better distribution in alloy. The melt temperature was maintained at $800{ }^{\circ} \mathrm{C}$ for 30 minutes, so that $\mathrm{Ca}$ and $\mathrm{Cu}$ got dissolve into the melt uniformly. Castings were prepared by pouring the melt into preheated cast iron mould of cylindrical shapes. For compressive behavior observations, Al-Ca-Cu alloy sample were cut, in cylindrical shape. The polished sample ware etched with Keller's reagent

\subsection{Compressive Deformation:}

Compression test were performed on Universal Testing Machine at varying strain rates $(0.001 / \mathrm{s}, 0.01 / \mathrm{s}$, $0.1 / \mathrm{s}, 1 / \mathrm{s}$ ) in room temperature condition. The dimension of the samples is $10 \mathrm{~mm}$ in diameter and $15 \mathrm{~mm}$ in length were prepared from the castings. The face were policed and lubricated with Teflon to reduce the friction between the specimen surface and the anvil or the punch. The engineering stress and engineering strain data were recorded from the digital display and these data were used for getting true stress -true strain curves. These data were further analyzed for determination of the strain hardening exponent, the plastic strength coefficient and the strain rate sensitivity.

\subsection{Compressive deformation:}

\section{Results:}

The true stress-strain curves of the investigated material when tested at different are shown in the fig. 1 fig.2 and fig.3. From these true stress-true strain plots, the yield stress and flow stress at different strain are determined using a standard methodology. It may be noted that the curves do not show any sharp yield point. The Composition of Al-Ca-Cu at $0.5 \% \mathrm{Cu}$ having elastic limit in between $52.71 \mathrm{MPa}$ to $64.61 \mathrm{MPa}$. See fig.1 The Composition of Al-Ca-Cu at $1 \% \mathrm{Cu}$ having elastic limit in between $34.58 \mathrm{MPa}$ to $52.94 \mathrm{MPa}$ fig. 2 The Composition of $\mathrm{Al}-\mathrm{Ca}-\mathrm{Cu}$ at $1.5 \% \mathrm{Cu}$ having elastic limit in between $34.72 \mathrm{MPa}$ to $62.95 \mathrm{MPa}$ see Fig. 3

In general, it is noted that there is no sharp yield point .There is gradual change from yielding to plastic region. In the plastic region stress increases gradually with strain indicating strain hardening. As there is no sharp yield point, so the $0.2 \%$ proof stress criteria is used to calculate yield stress $\left(\sigma_{y}\right)$. For better evaluation of yield stress, elastic limit stress $\left(\sigma_{\mathrm{e}}\right)$ was determined [14]. The Strain rate sensitivity is calculated as per standard method [15]

$$
\sigma_{\mathrm{f}=\mathrm{K}} \varepsilon^{\mathrm{m}}
$$

$$
\begin{aligned}
& \text { Where } \\
& \mathrm{K}=\text { Plastic Strength Coefficient } \\
& \mathrm{m}=\text { Strain Rate Sensitivity } \\
& \sigma_{\mathrm{f}}=\text { Flow Stress (MPa) } \\
& \varepsilon=\text { Strain Rate }
\end{aligned}
$$

In the elastic region $\sigma=\mathrm{E} \varepsilon$, where $\mathrm{E}$ is the elastic modulus and $\epsilon^{-}$is the strain; the above equation can be written as follows

$$
\ln (\sigma)=\ln (\mathrm{K})+\mathrm{n} \ln (\varepsilon) .
$$

The $\ln (\sigma) \mathrm{Vs} \ln (\varepsilon)$ plots are drawn from the recorded true stress and true strain data. Each of the plots led to two lines having different shapes (for plastic and elastic region), which appear to be intersecting at a point. The equation of the lower (elastic region) and the upper line (plastic region) could be assumed as follows: [15]

Where, $\mathrm{y}=\ln (\sigma)$

$$
\begin{aligned}
& y=a_{1} x+b_{1} \\
& y=a_{2} x+b_{2}
\end{aligned}
$$

$\mathrm{x}=\ln (\varepsilon)$

$a_{1} \& a_{2}=$ Intercept of upper line and lower line respectively $b_{1} \& b_{2}=$ Slope of upper line and lower line respectively Thus a1 is equal to the strain hardening exponent and $\mathrm{b} 1$ is the $\ln (\mathrm{K})$. If it is assumed that at the point of elastic limit, the two lines will intercept, then by equating the above two equations, one can get the value of $y$ in terms of $a_{1}, b_{1}, a_{2}, b_{2}$

$$
y=\left\{\left(a_{1} b_{2}-a_{2} b_{1}\right) /\left(a_{1}-a_{2}\right)\right\} \ldots \ldots
$$


Table.1 Elastic limit, plastic strength coefficient, proof stress and strain hardening exponent.

\begin{tabular}{|c|c|c|c|c|c|}
\hline $\begin{array}{c}\mathrm{Cu} \\
\text { Contents }\end{array}$ & St.Rate & $\begin{array}{c}\text { Strain hardening } \\
\text { exponent } \\
\left(n=a_{1}\right)\end{array}$ & $\begin{array}{c}\text { Elastic limit } \\
\left(\sigma_{\mathrm{e}}=\mathrm{e}^{\mathrm{y}}\right) \\
\mathrm{MPa} \\
\end{array}$ & $\begin{array}{c}\text { Plastic Strength } \\
\text { coefficient } \\
\left(\mathrm{k}=\mathrm{e}^{\mathrm{b} 1}\right) \mathrm{MPa}\end{array}$ & $\begin{array}{c}\text { Proof Stress } \\
\left(\sigma_{y}\right) \\
\text { MPa }\end{array}$ \\
\hline \multirow{4}{*}{$0.50 \%$} & $0.001 / \mathrm{s}$ & 0.426 & 52.71469215 & 254.7544143 & 55.843 \\
\hline & $0.01 / \mathrm{s}$ & 0.42 & 55.92122676 & 242.0200896 & 56 \\
\hline & $0.1 / \mathrm{s}$ & 0.435 & 52.79785623 & 227.0113463 & 59 \\
\hline & $1 / \mathrm{s}$ & 0.472 & 64.61101064 & 207.6803253 & 63.127 \\
\hline \multirow{4}{*}{$1.00 \%$} & $0.001 / \mathrm{s}$ & 0.42 & 34.58407938 & 235.3326394 & 36.768 \\
\hline & $0.01 / \mathrm{s}$ & 0.447 & 38.12674576 & 231.8662197 & 38.56 \\
\hline & $0.1 / \mathrm{s}$ & 0.421 & 52.94855891 & 225.4278157 & 56.37 \\
\hline & $1 / \mathrm{s}$ & 0.468 & 48.08777164 & 224.0792984 & 46.428 \\
\hline \multirow{4}{*}{$1.50 \%$} & $0.001 / \mathrm{s}$ & 0.456 & 62.95762802 & 232.5255241 & 62.15 \\
\hline & $0.01 / \mathrm{s}$ & 0.492 & 44.15031227 & 240.5673279 & 47.546 \\
\hline & $0.1 / \mathrm{s}$ & 0.49 & 34.72404171 & 216.1559202 & 37.214 \\
\hline & $1 / \mathrm{s}$ & 0.455 & 44.34293286 & 195.5859647 & 43.37 \\
\hline
\end{tabular}

Table .2 Variation of Strain Rate sensitivity $(m)$ and Strength Coefficient $\left(K_{s}\right)$ with Strain of Compression test result.

\begin{tabular}{|c|c|c|c|}
\hline Cu-Content & Strain & Strain rate sensitivity (m) & Strength coefficient $\left(\mathbf{K}_{\mathbf{s}}\right)$ \\
\hline \multirow{5}{*}{$0.5 \%$} & 0.05 & -0.07 & 50.40044478 \\
\cline { 2 - 4 } & 0.1 & -0.035 & 80.47929932 \\
\cline { 2 - 4 } & 0.15 & -0.036 & 103.855447 \\
\cline { 2 - 4 } & 0.2 & -0.031 & 115.2380513 \\
\cline { 2 - 4 } & 0.25 & -0.026 & 64.650769 \\
\hline \multirow{5}{*}{$1 \%$} & 0.05 & 0.056 & 86.05615085 \\
\cline { 2 - 4 } & 0.1 & 0.04 & 101.1900063 \\
\cline { 2 - 4 } & 0.15 & 0.028 & 116.1636532 \\
\cline { 2 - 4 } & 0.2 & 0.025 & 123.2235272 \\
\cline { 2 - 4 } & 0.25 & 0.015 & 27.743 \\
\hline \multirow{5}{*}{$1.5 \%$} & 0.05 & -0.161 & 48.91088652 \\
\cline { 2 - 4 } & 0.1 & -0.109 & 63.49746603 \\
\cline { 2 - 4 } & 0.15 & -0.09 & 72.24044001 \\
\cline { 2 - 4 } & 0.2 & -0.088 & 84.69020911 \\
\cline { 2 - 4 } & 0.25 & -0.074 & \\
\hline
\end{tabular}

\subsection{Effect of Cu Addition on the Al-Ca-Cu Alloy:}

The Al-Ca-Cu alloy is giving maximum value of elasticity in $0.5 \% \mathrm{Cu}$ at $1 / \mathrm{s}$ and minimum in $1 \% \mathrm{Cu}$ at $0.001 / \mathrm{s}$.And analyzing at all strain rate in all composition it is found that the value of elasticity varies with variation in $\mathrm{Cu}$ contents and strain rates . The value of plastic strength coefficient is found least in $1.5 \% \mathrm{Cu}$ at $1 / \mathrm{s}$ and maximum in $0.5 \% \mathrm{Cu}$ at $0.001 / \mathrm{s}$ thus it is found that plasticity also varies with the variation in $\mathrm{Cu}$ 
contents and strain rates. The yield stress of the $\mathrm{Al}-\mathrm{Ca}-\mathrm{Cu}$ alloy also varying with deferent $\mathrm{Cu}$ contents and strain rates. It has the maximum value in $0.5 \% \mathrm{Cu}$ at $1 / \mathrm{s}$ and least in $1 \% \mathrm{Cu}$ at $0.001 / \mathrm{s}$.
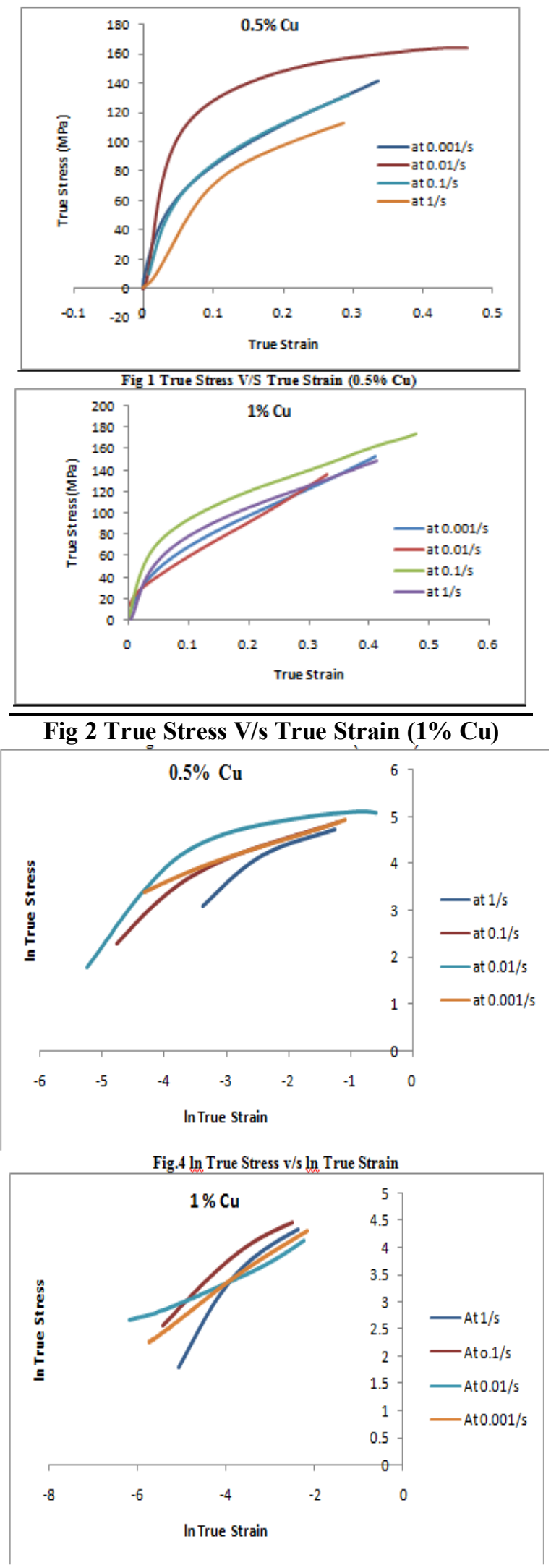

Fig.4 In True Stress v/s In True Strain 


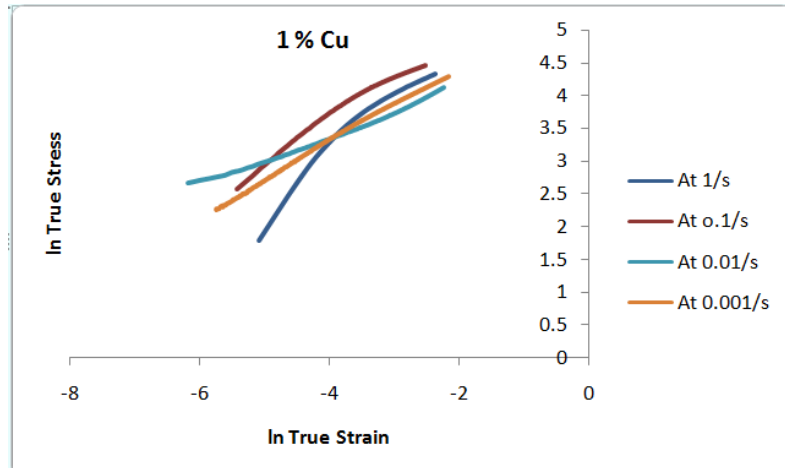

Fig 5 In True Stress v/s In True Strain

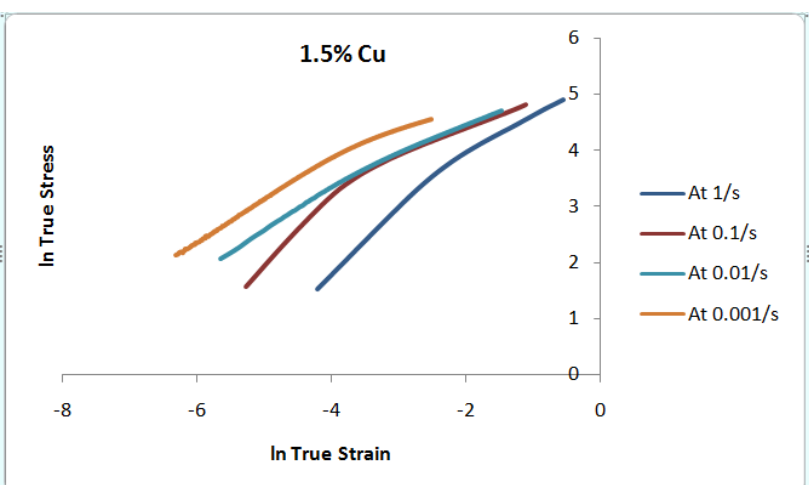

Fig.6 In True Stress v/s ln True Strain

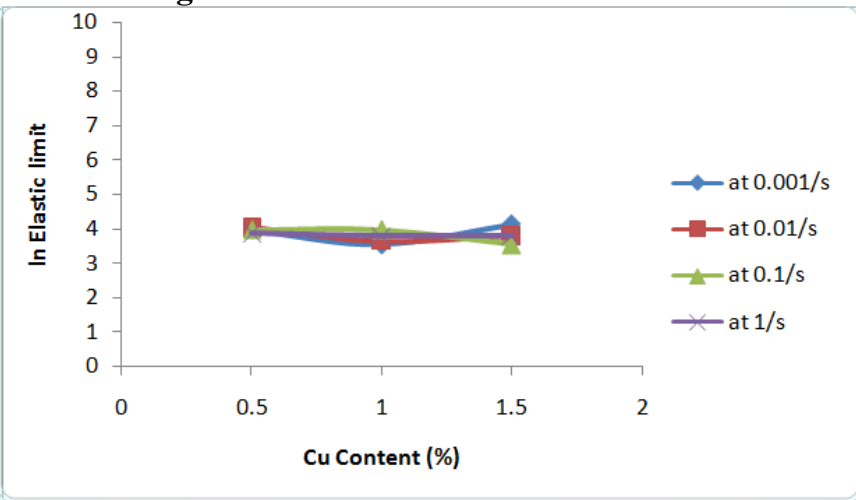

Fig 7 In Elastic limit v/s Cu Contents

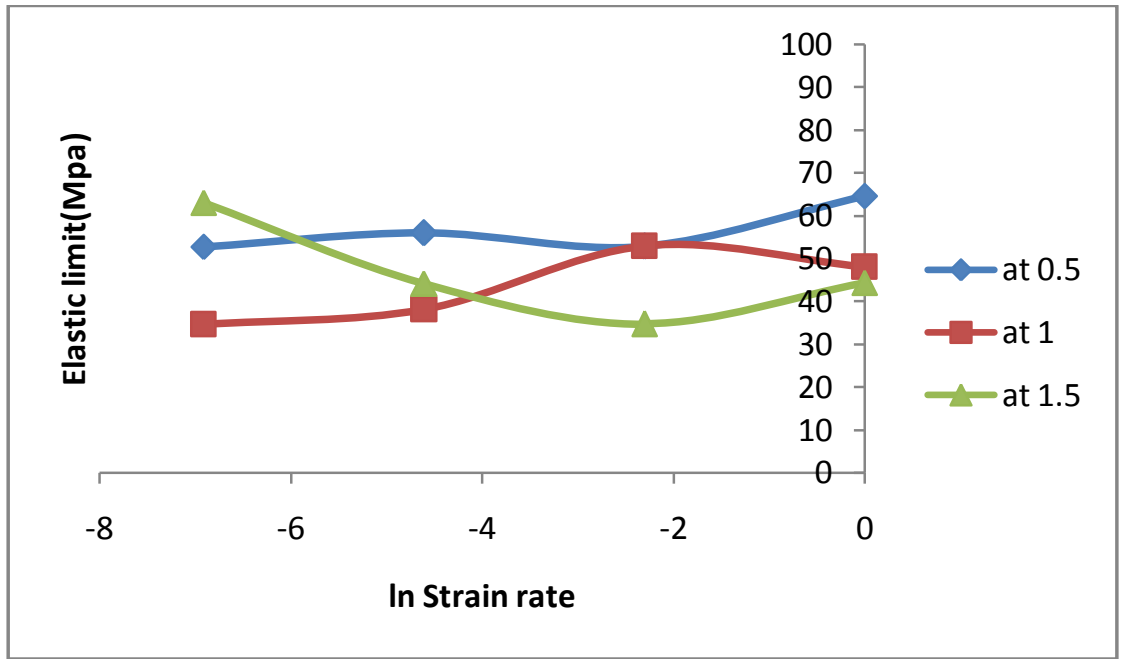

Fig. 8 Elastic limit stress v/s In Strain rate 


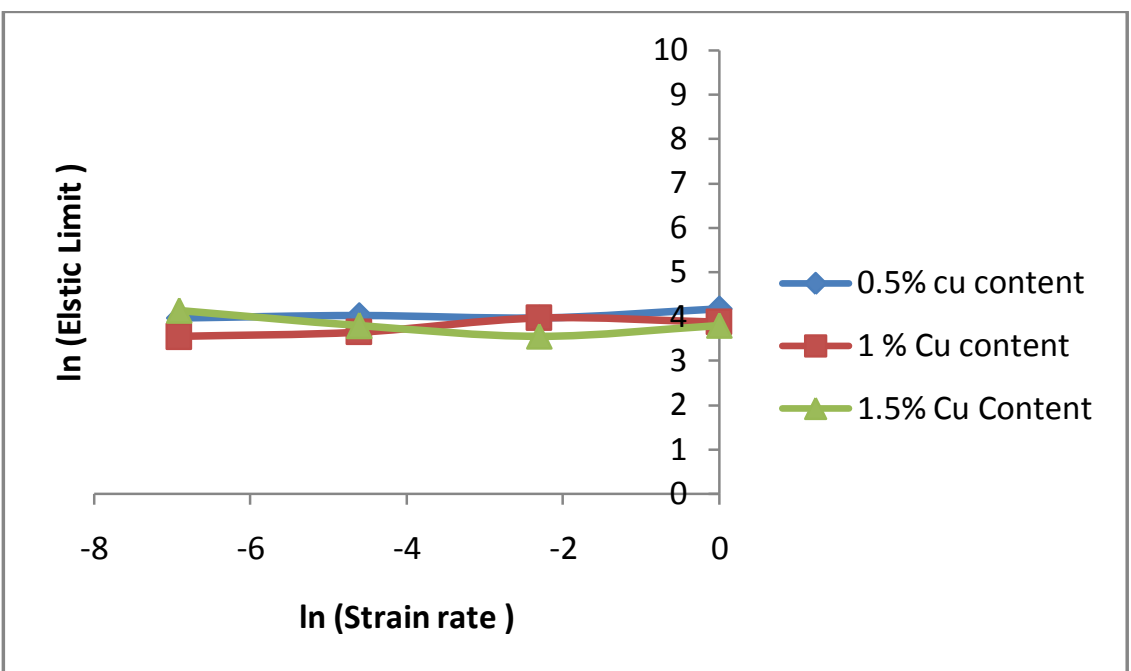

Fig 9 In Elastic limit v/s In Strain rate

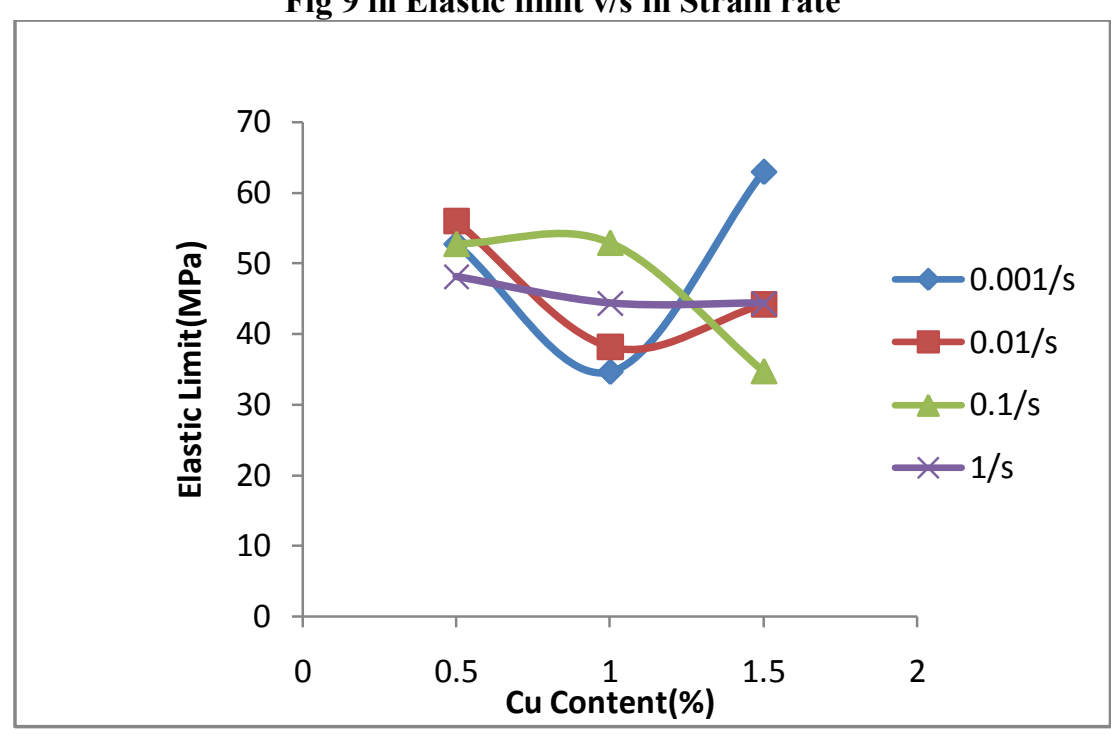

Fig.10 Elastic limit v/s Cu contents

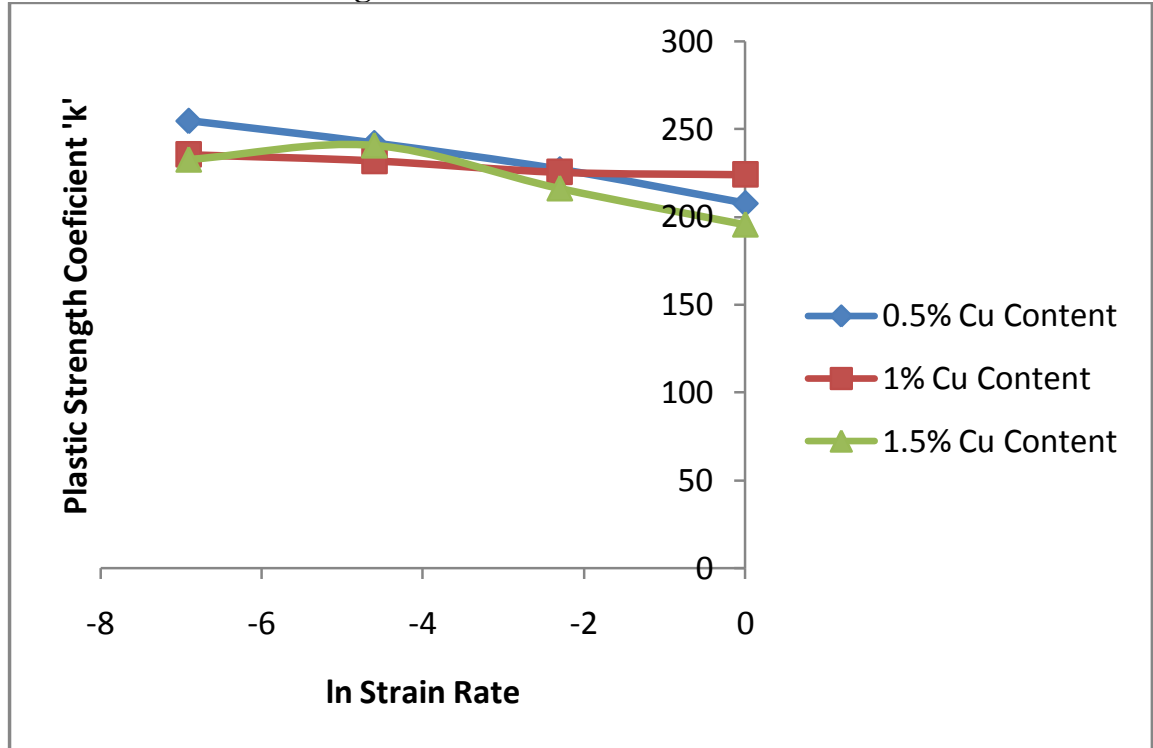

Fig.11 Plastic strength coefficient 'k' v/s In Strain rate 


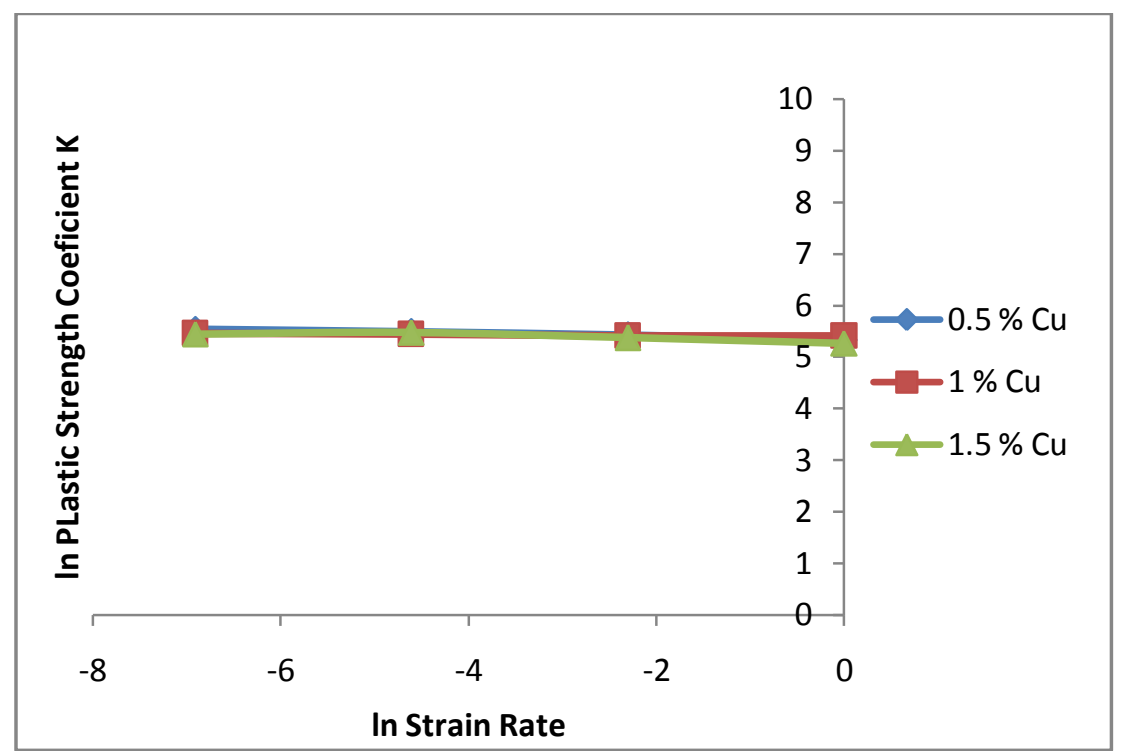

Fig 12 In Plastic Strength coefficient ' $k$ ' v/s In Strain rate

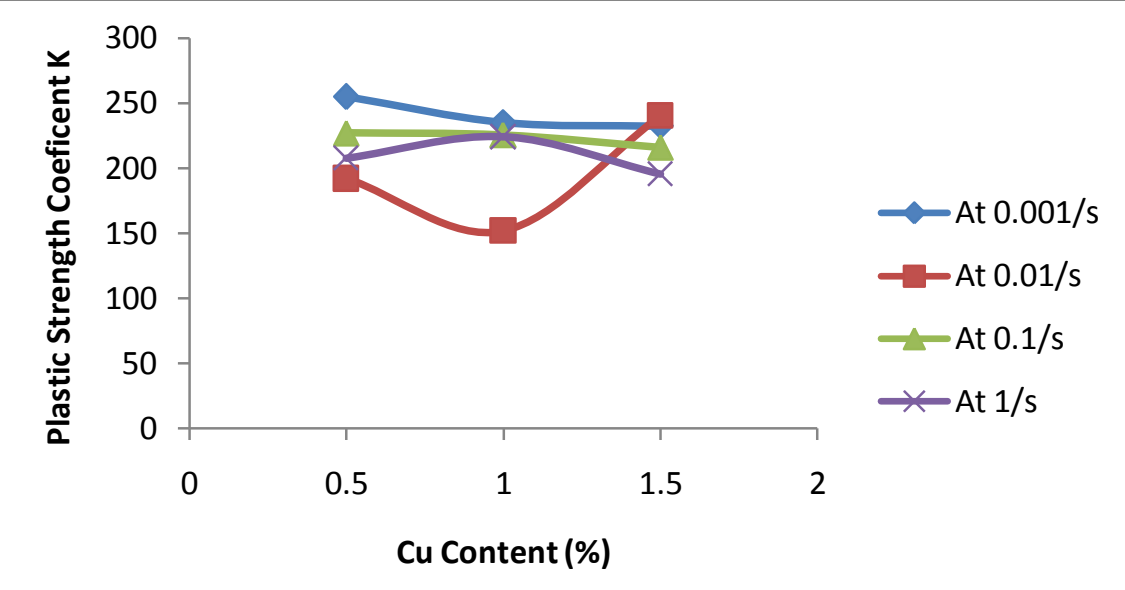

Fig.13 Plastic Strength coefficient 'k' v/s Cu Content

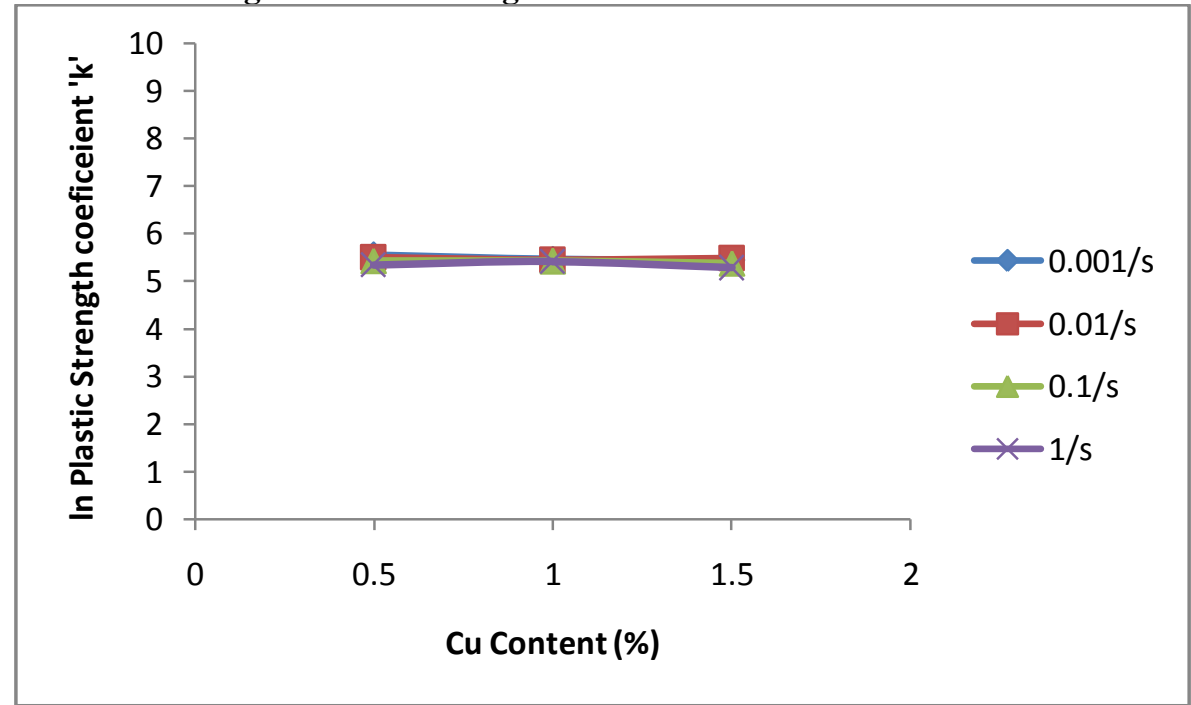

Fig. 14 In Plastic Strength Coefficient ' $k$ ' v/s Cu Content 


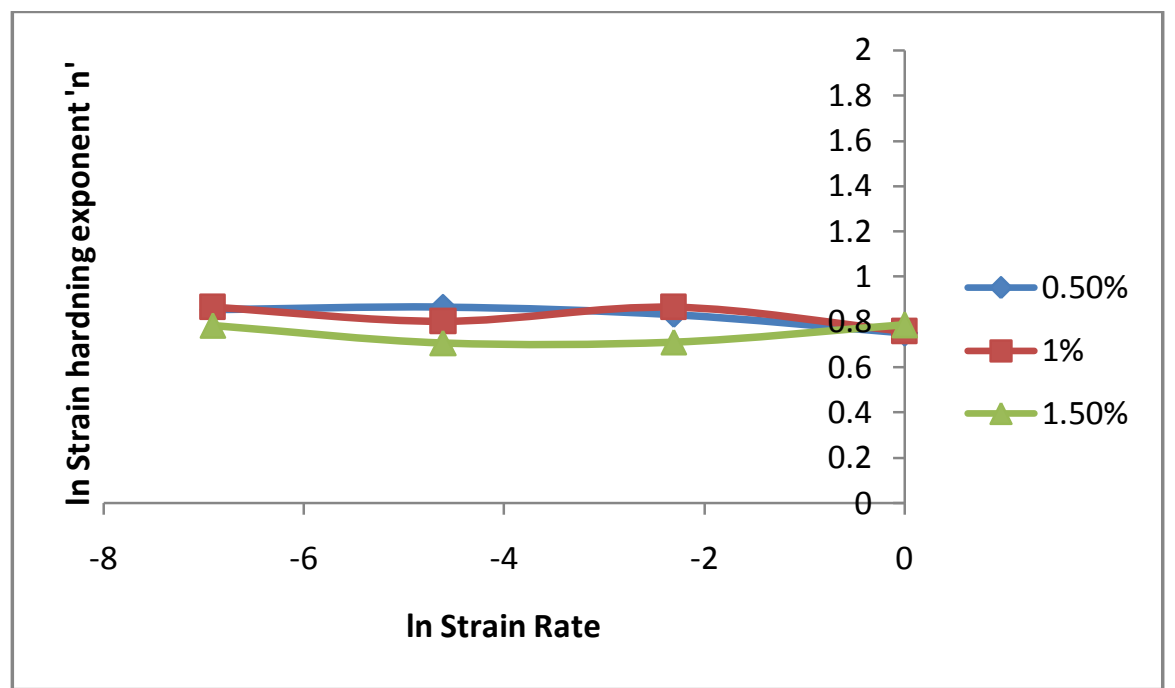

Fig.15 In Strain hardening exponent ' $n$ ' v/s In Strain rate

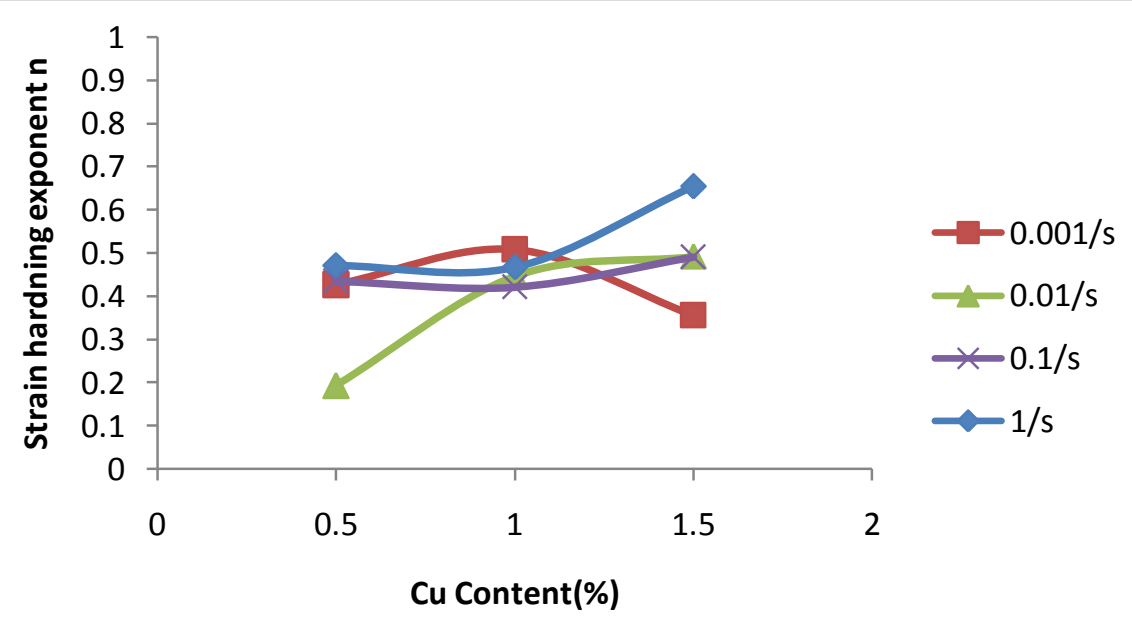

Fig.16 Strain hardening exponent ' $n$ ' v/s Cu content

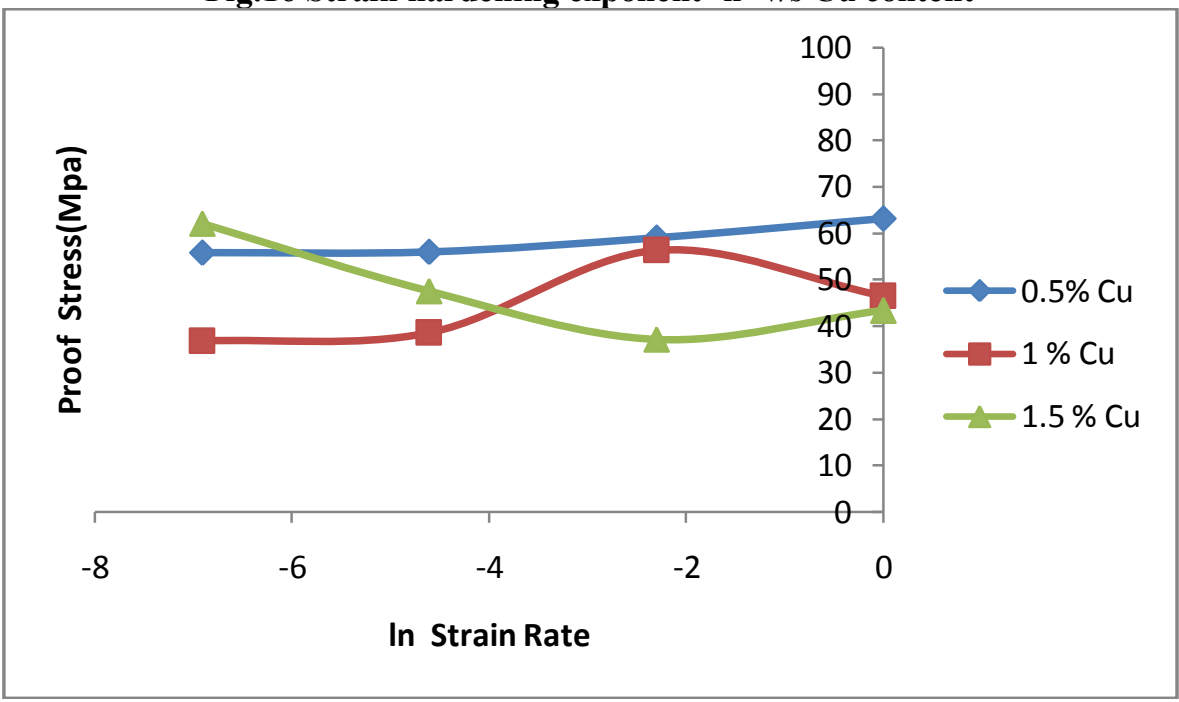

Fig.17 Proof Stress v/s In Strain rate 


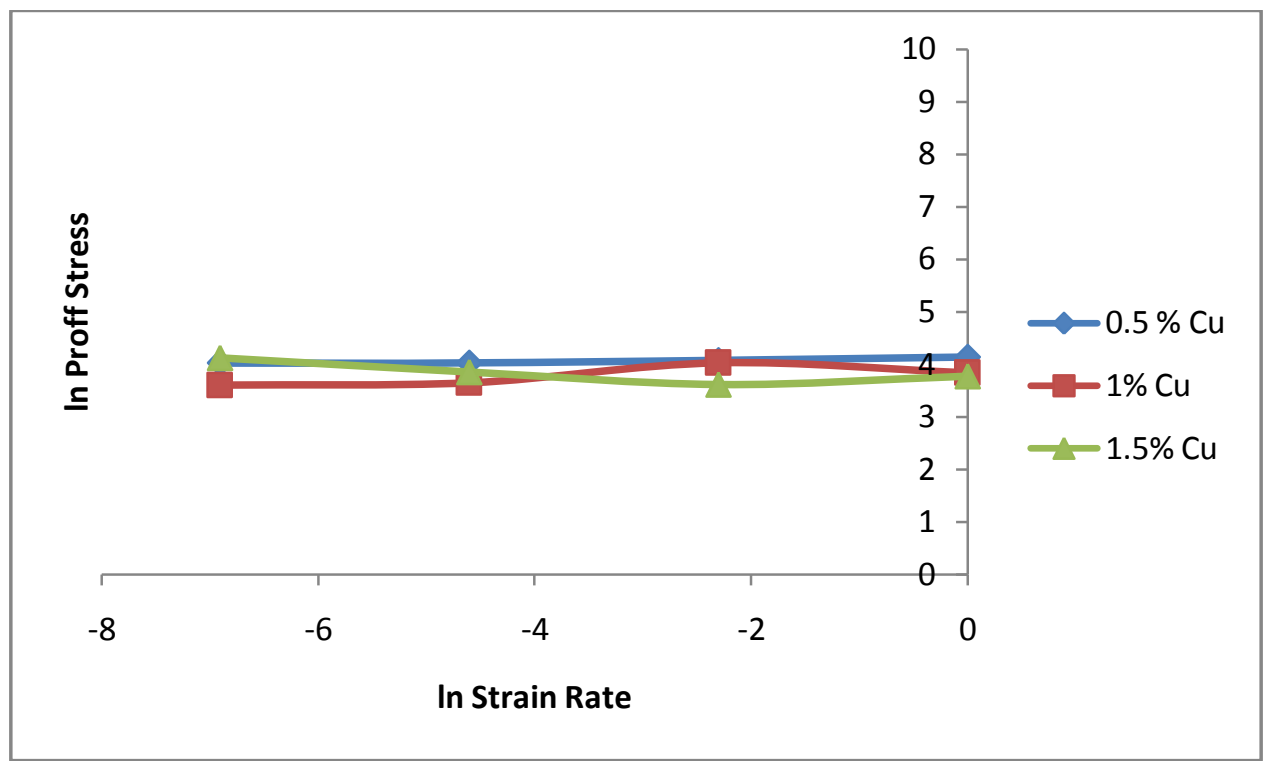

Fig.18 In Proof Stress v/s In Strain arte

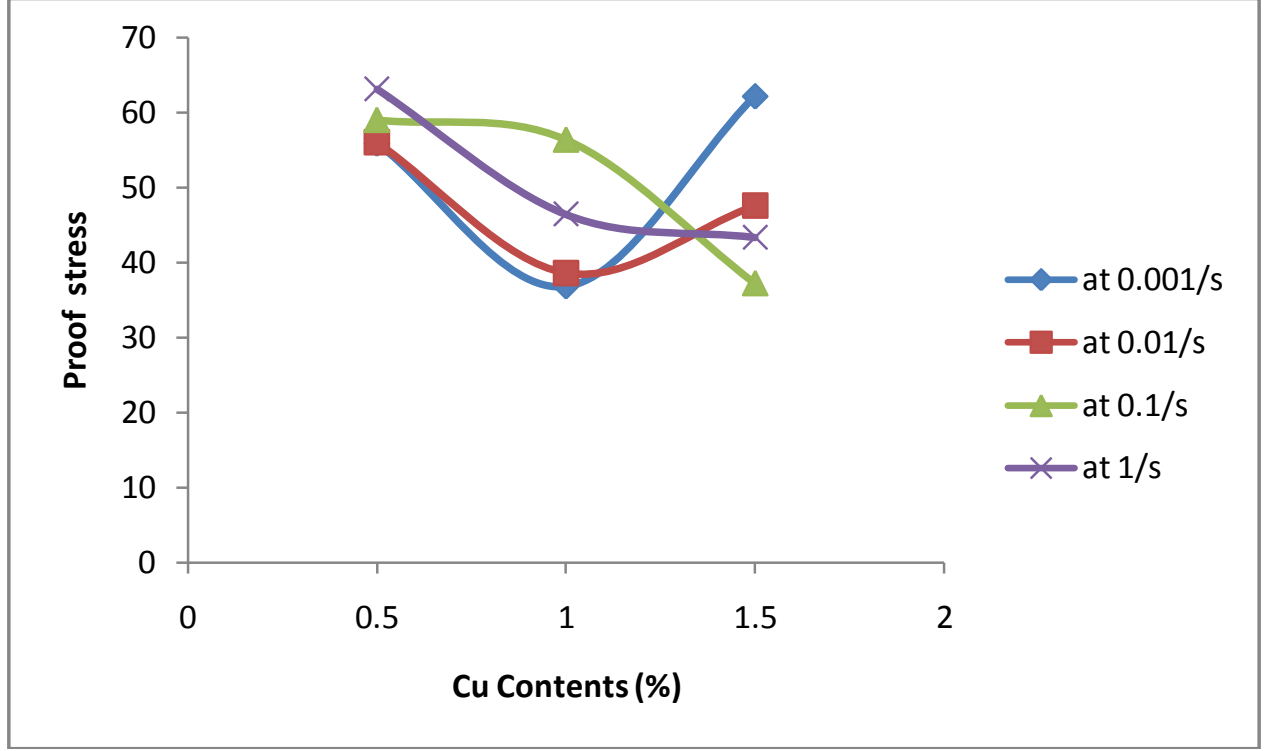

Fig.19 Proof Stress v/s Cu Contents

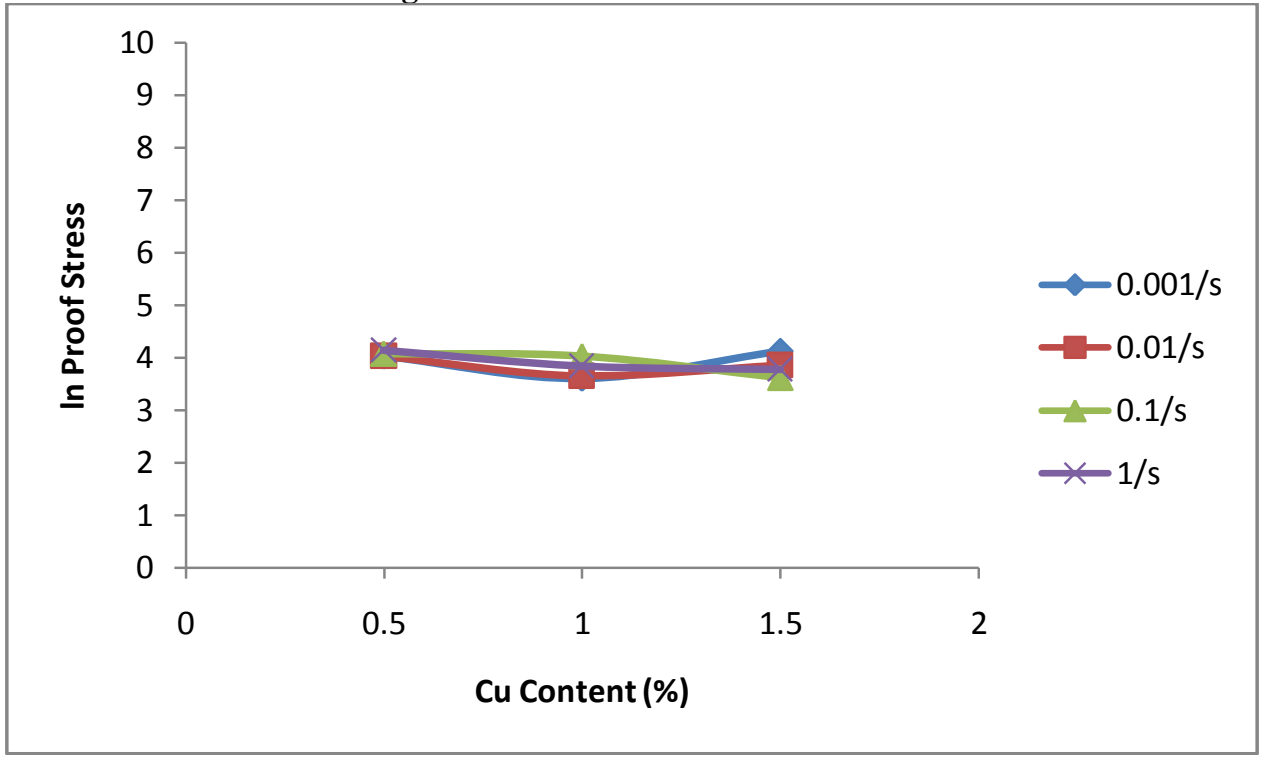

Fig. 20 In Proof Stress v/s Cu Content 


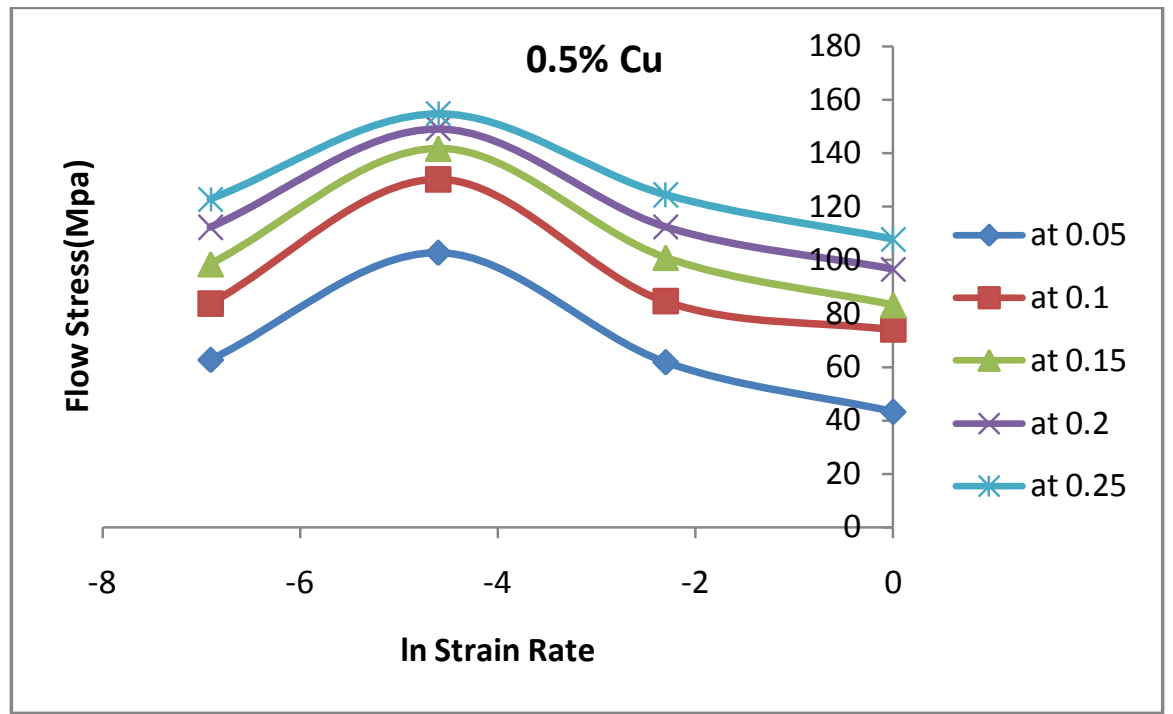

Fig 21 Flow Stress v/s In Strain Rate

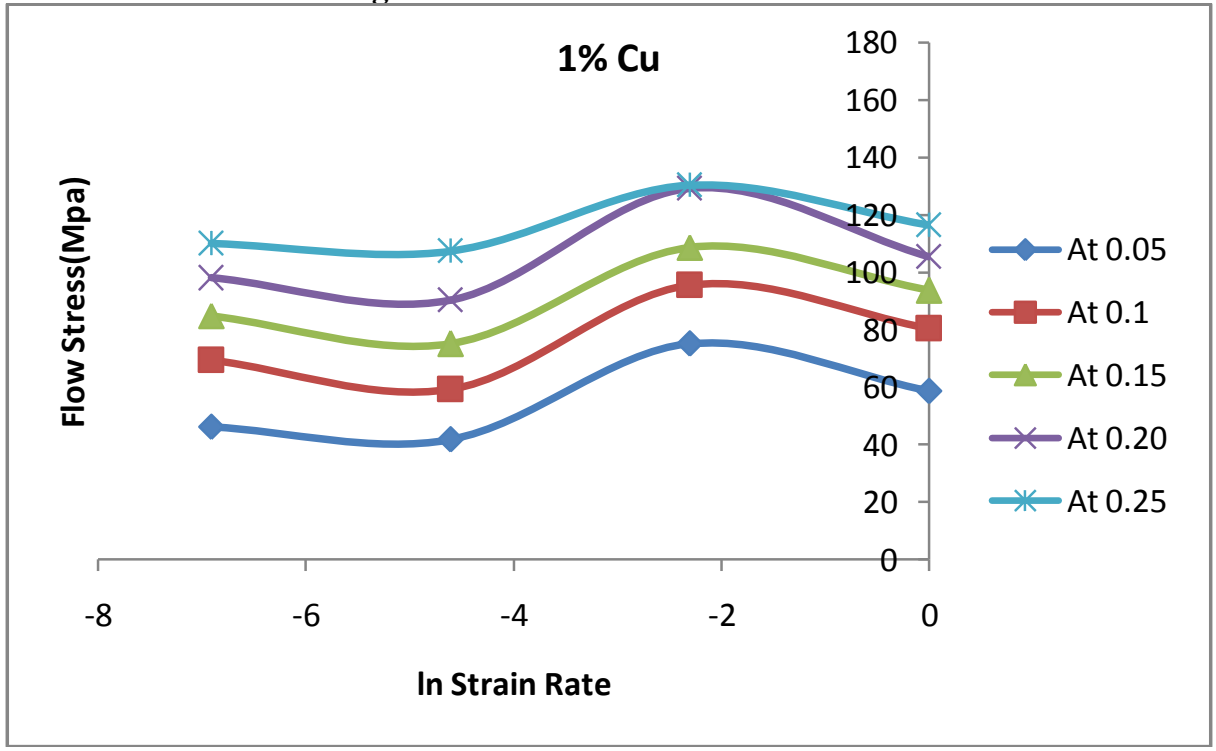

Fig. 22 Flow Stress v/s In Strain Rate

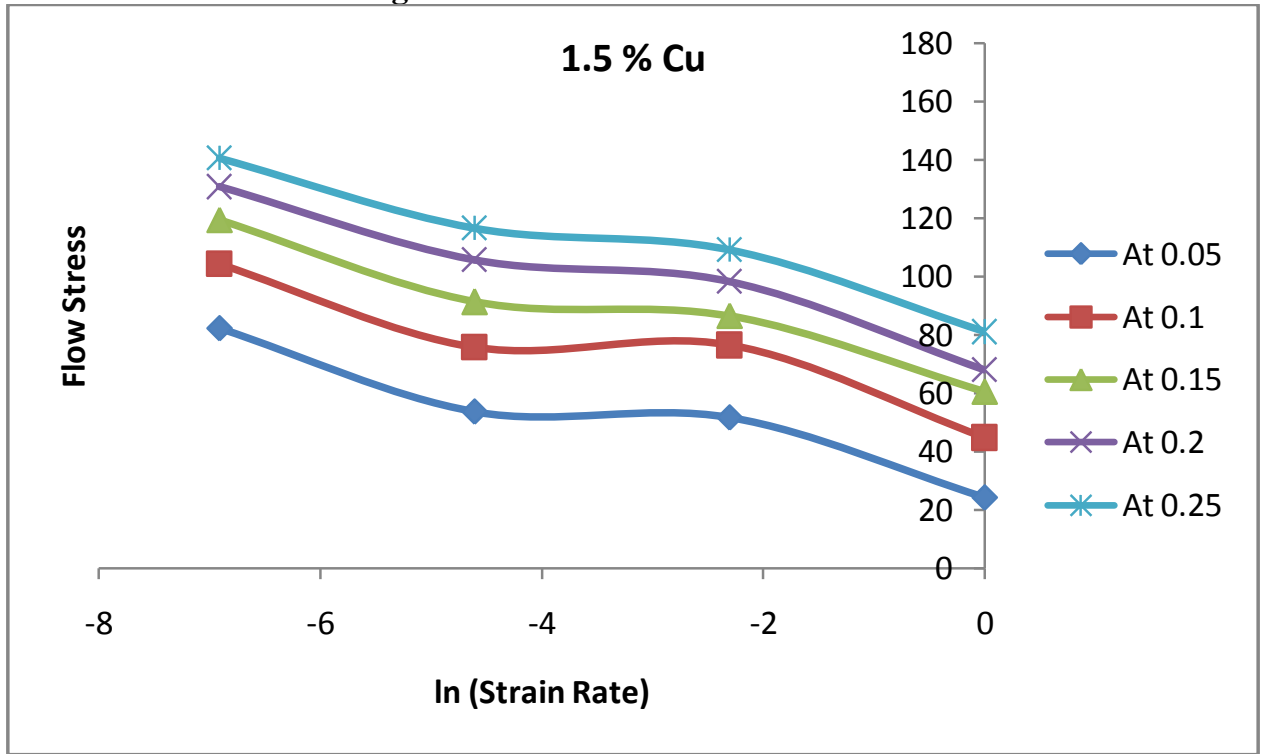

Fig 23 Flow Stress v/s In (Strain Rate) 


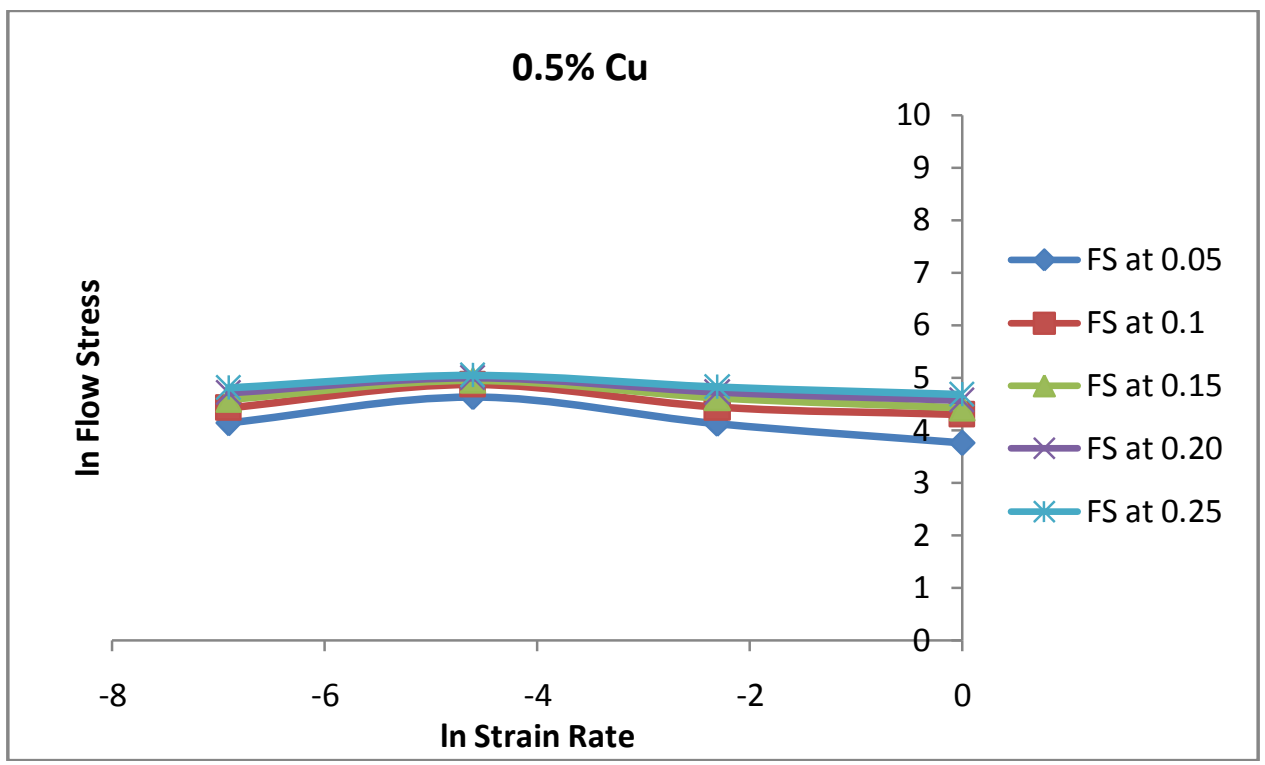

Fig. 24 In Flow Stress v/s In Strain Rate

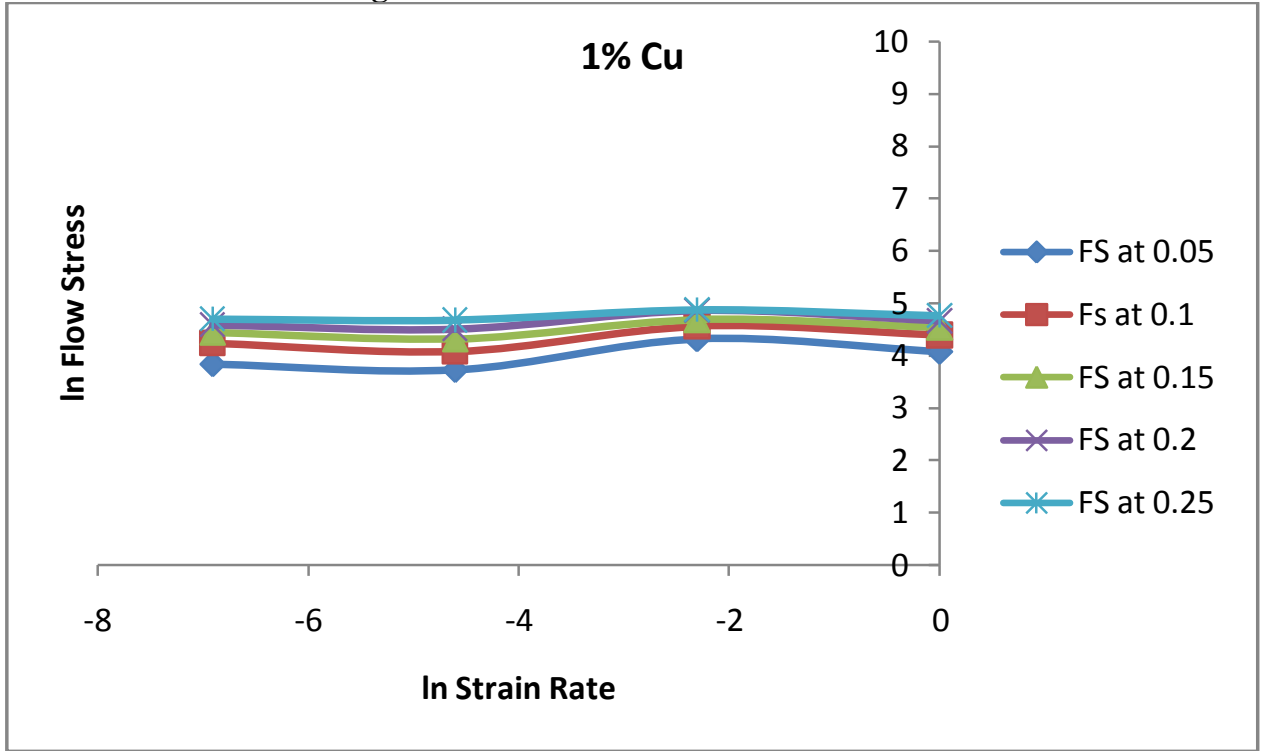

Fig 25 In Flow Stress v/s In Strain Rate

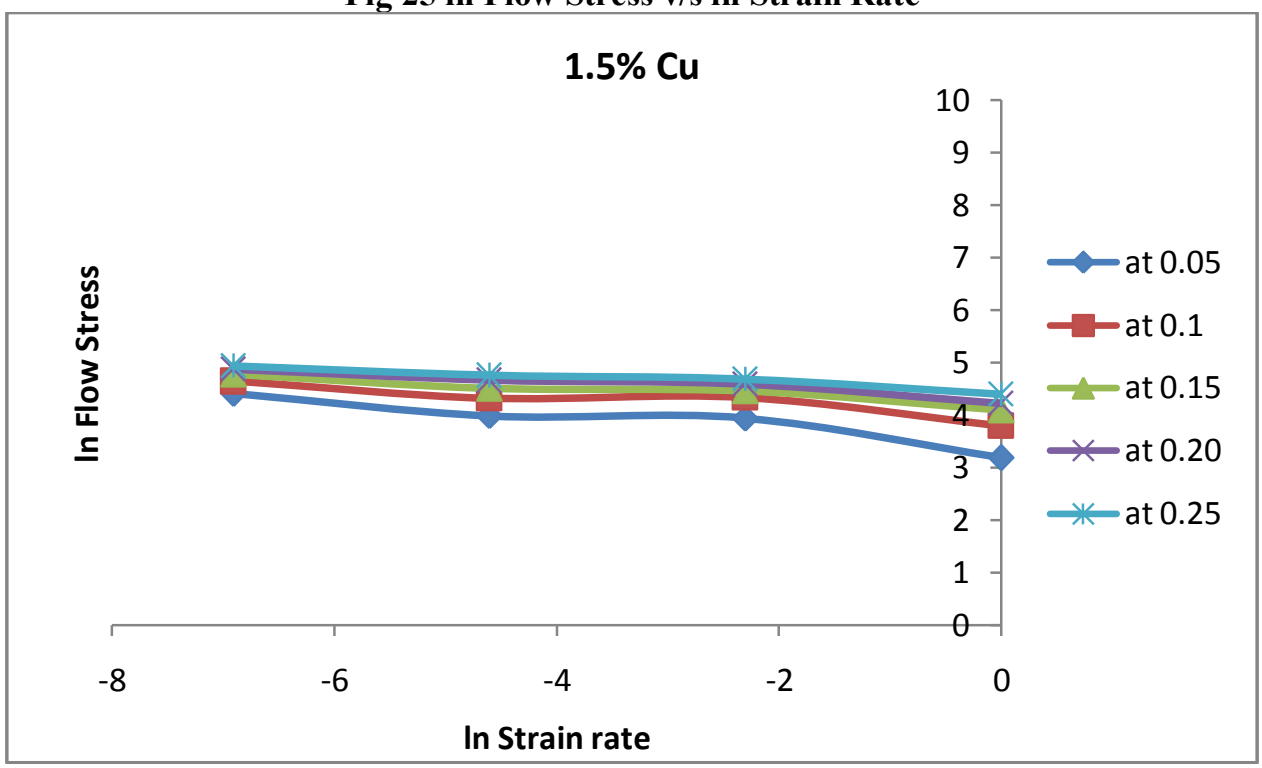

Fig. 26 In Flow Stress v/s In Starin Rate 


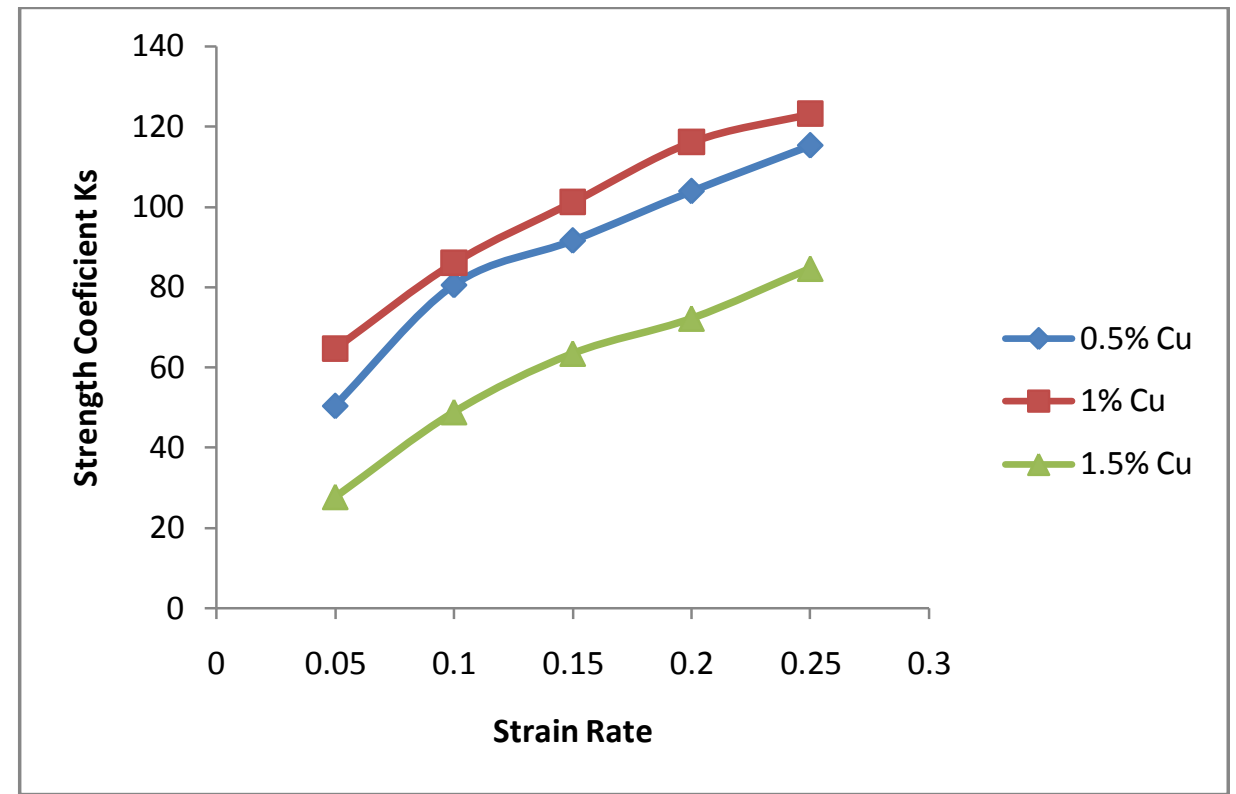

Fig. 27 Strength Coefficient 'Ks' v/s Strain Rate

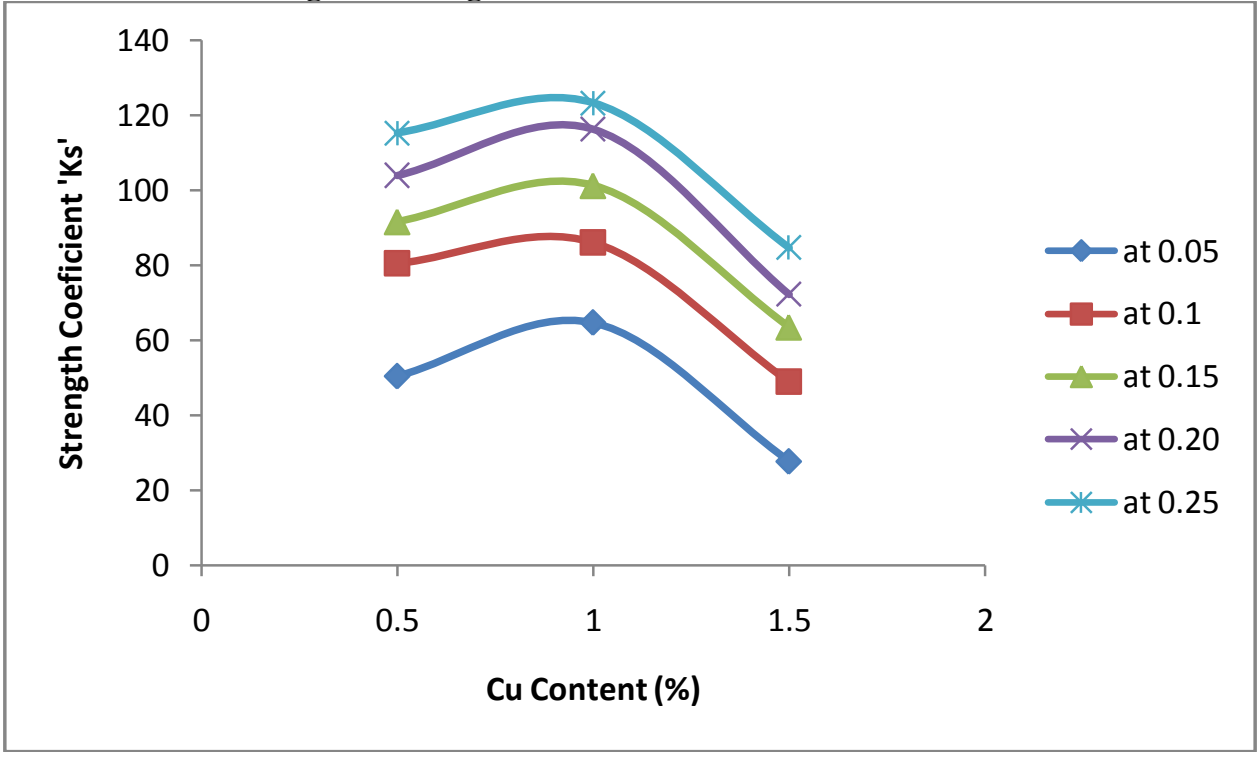

Fig. 28 Strength Coefficient 'Ks' v/s Cu Content

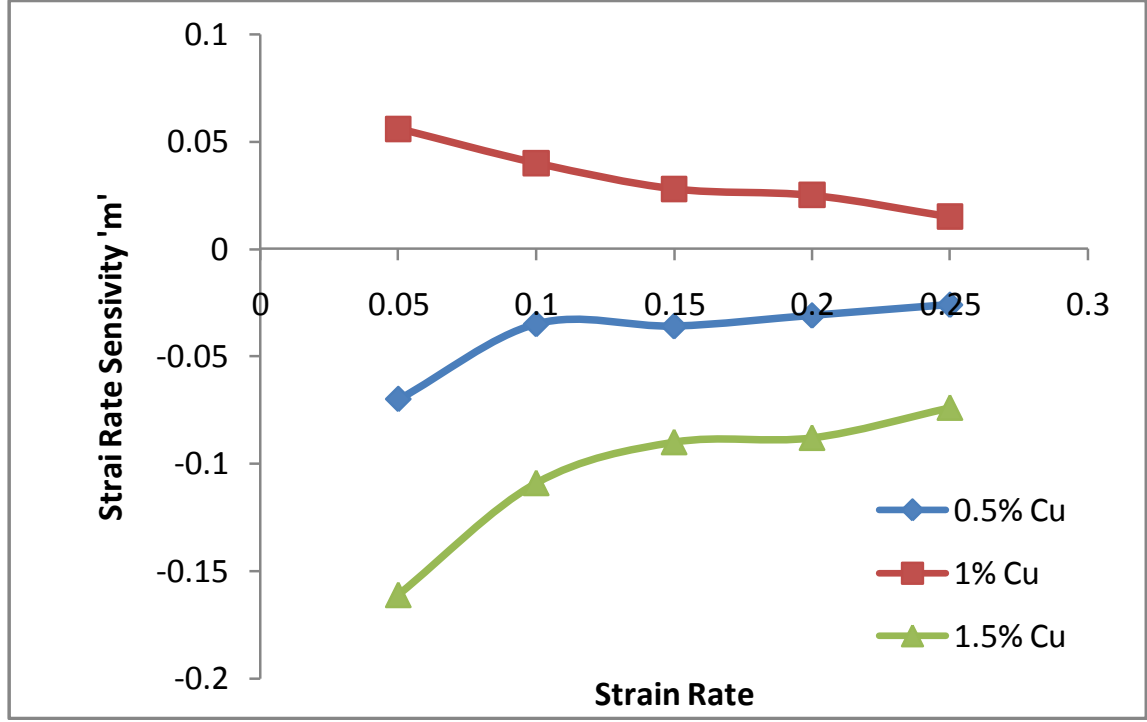

Fig.29 Strain Rate sensitivity ' $m$ ' v/s Strain Rate 


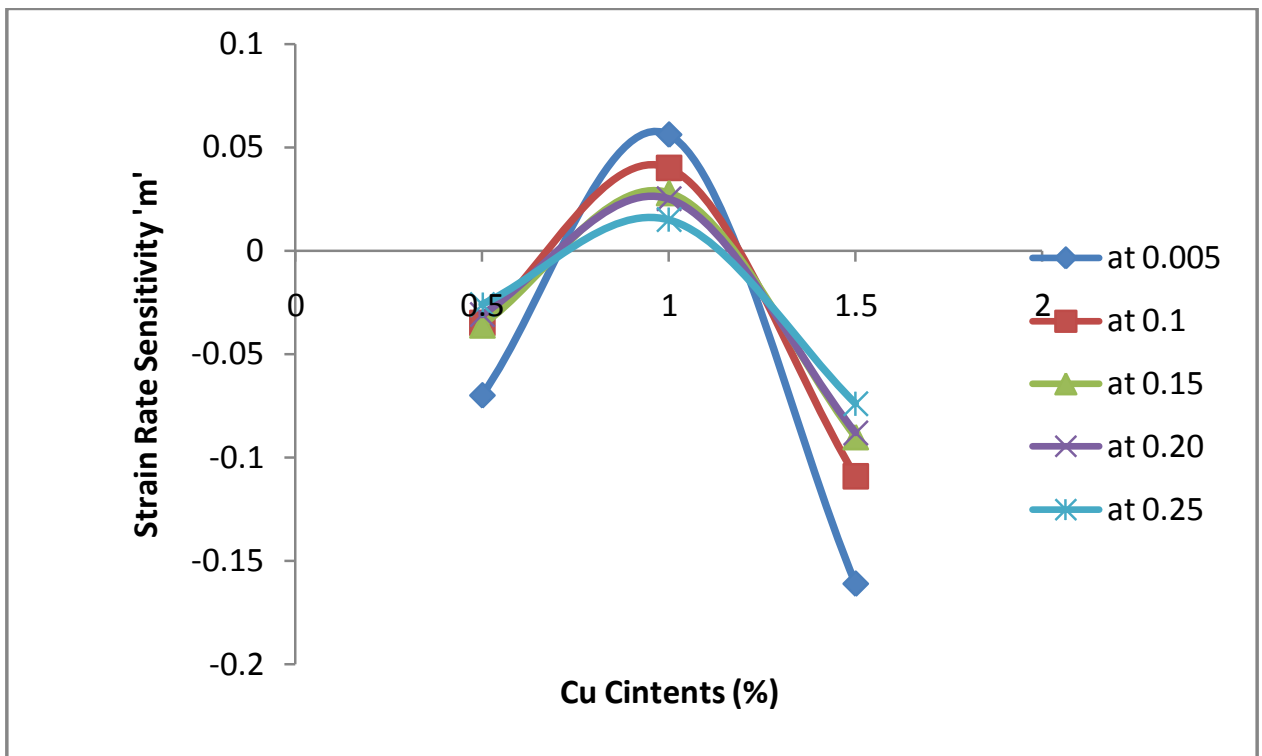

Fig. 30 Strain Rate Sensitivity 'm' v/s Cu Contents

\section{Conclusion:}

The following are the conclusion:

1. The flow curves of $\mathrm{Al}-\mathrm{Ca}-\mathrm{Cu}$ having $0.5 \%, 1 \%$, and $1.5 \%$, of $\mathrm{Cu}$ exhibits different trend with respective of strain rate. The yielding of $0.5 \%, 1 \%$ and $1.5 \%$ of $\mathrm{Cu}$ alloy at different strain rates starts at $63 \mathrm{MPa}, 56 \mathrm{MPa}$ and $62 \mathrm{MPa}$ respectively.

2. The alloy containing $0.5 \% \mathrm{Cu}$ having highest ductility as well as it has also highest strength.

3. The yield stress and the elastic limit stress are calculated from the stress-strain curves are has the different values with respect to different strain rate of different composition.

4. The Al-Ca-Cu alloy having $0.5 \% \mathrm{Cu}$ has maximum value elastic emit and least of plastic strength coefficient.

5. The Strain hardening exponent having maximum value at $0.5 \% \mathrm{Cu}$ Content $\mathrm{Al}-\mathrm{Ca}-\mathrm{Cu}$ alloy.

6. The Strain Rate Sensitivity of this alloy is very low. The maximum value of strain rate sensitivity $(0.015)$ is achieved in $1 \% \mathrm{Cu}$. These values strongly demonstrate that compressive deformation of $\mathrm{Al}-\mathrm{Ca}-\mathrm{Cu}$ alloys almost independent to the strain rate at room temperature deformation.

7. Strength coefficient has the maximum value in $1 \% \mathrm{Cu}$ of Al-Ca-Cu alloy .

\section{References}

[1] Vadim S Zoloito revsky, Nikolai A.belov, Michael V.Glazoff. 'Casting Aluminum alloys'. ( 2007)

[2] Miller WS, Heinz A, Haszler A, Keidel C, Moldenhauer S, Benedictus R.'Recent development in aluminium alloys for aerospace applications.' Mater Sci Eng A (2000) 280:102-7.

[3] Strake EA, Staley JT. 'Applications of modern aluminum alloys to aircraft.' Progress Aerospace Sci (1999) 32:131-72.

[4] Froes FH. 'Advanced metals for aerospace and automotive use.' Mater Sci Eng A (1994) 184:119-33.

[5] Starke EA. 'Aluminum: alloying. Encyclopedia.' Mater Sci Technol (2008) 101-8.

[6] Heusler Leonhard, Schneider Wolfgang. 'Influence of alloying elements on the thermal analysis of Al-Si cast alloys.' J Light Metals (2002) 2:17-26.

[7] Manas Dash, Makhlouf Makhlouf. 'Effect of key alloying elements on the feeding characteristics of aluminium silicon casting alloys.' J Light Metals (2001) 1:251-65.

[8]. Atrens, A.; Nairn, J.; Fernee, H.; FitzGerald, K.; Skennerton, G.; Olofinjana, A. Mater. Forum 1997, 21 , 57 'Comprehensive of nuclear material' in (1997)

[9]. Taubenblat, P. W.; Smith, W. E.; Graviano, Ling, E., Taubenblat, P. W. 'A. R. In High Conductivity Copper and Aluminum Alloys' Eds.; Metallurgical Soc of AIM: Warrendale, PA, (1984); p 19

[10]. Lu, L.; Shen, Y.; Chen, X.; Qian, L.; Lu, K. Science 'Ultrahigh strength and high electrical conductivity in copper.' Chinese Academy of Sciences, Shenyang 110016, P.R. China. (2004), 304, 422

[11] Rudy J.M. Konings, Todd R.Allen, Roge E Stoller, Shinsuke Yamanka 'Comprehensive Nuclear Material'.( 2011)

[12] D.P.Mondal ,Nidhi Jha ,Anshul Badkul, S.Das , M.S.Yadav,Prabhash Jain "Effect of calcium addition on the microstructure and compressive deformation behavior of 7178 Aluminum alloy" Material and Design 32 (2011)2803-2812

[13] Project by Prabhash Jain, Satish Shiramdash, Rajdeep Singh Parihar, Rajkaran Singh ,Nishi Kumar Sinha "Effect of Calcium addition on deformation behavior of Aluminum Alloys" at BUIT Bhopal ,India. (2011)

[14] Strength of Material by John Symonds ,J.P.Vidosic, Harold V Hawkins, Donald D.Doge

[15] D.P.Mondal, S.Das, N.V.Ganesh, V.S.Muneshwar, N.Ramakrishnan "Effect of Sic concentration and strain rate on the compression deformation behavior of 2014Al-SiCp composite" 